\title{
Impact of Socialization on Employee's Reputation
}

\author{
Arafat Adeel (Corresponding Author) \\ Karachi University Business School \\ Karachi University Business School, University of Karachi, Karachi, Pakistan \\ E-mail: arafatadeel@gmail.com
}

Dr. Muhammad Asim

Associate Professor, Karachi University Business School

University of Karachi, Karachi, Pakistan

E-mail: masimku@hotmail.com

Received: April 7, 2019 Accepted: April 29, 2019 Online published: May 15, 2019

doi:10.5296/ijhrs.v9i2.14619 URL: https://doi.org/10.5296/ijhrs.v9i2.14619

\begin{abstract}
The aim of this study was to analyze whether the impact of socialization on new employees' reputation is positive or negative. To aware the potential employees about factors that can help in bringing out constructive rapport in the professional life, it was important to explore the importance of socialization and forming association in the organization. Variables studied were socialization, grouping, relationship with other employees, and new employees' reputation. A sample size of 250 respondents was taken for data screening to carry out this research through simple random sampling technique. This was correlative research and multiple linear regression analysis was used to check the impact of independent variables on employee's reputation. It was a quantitative as well as qualitative research and data was collected by distributing questionnaires. The result suggested that socialization and association with your colleagues play a vital role in creating good reputation while grouping will not be that helpful. The employees can be social and perform team building attitude rather than forming a group. The study tells about the importance and the level of overall socialization an employee must pursue to get promotion. The balanced socialization can help employee in building up rapport when he is a new entrant in any organization.
\end{abstract}

Keywords: socialization, employee reputation, employee relationship 


\section{Introduction}

We often encounter situations where organizations recruit employees that makes some new entrants feel competent, whereas others helpless. They make some perceive themselves as effective as helpful organization members and make others feel rejected or detached? Also catering to making some employees feel like actively contributing towards the organization while making others passive observers?

Different employees bring number of different differences to work. It is because they all have variety of attitudes, personalities, and values. They have different ways of perceiving situations, react differently under pressure, and have different problem-solving methods. When these individuals enter into their respective organizations, their stable characteristics and traits affect their behavior and performance. Furthermore, the companies as well, hire people with expectations that those individuals possess certain abilities, knowledge, values, skills, and personalities which would cater to the organization and prove beneficial for both the work environment and the work itself (Carpenter, Bauer, \& Erdogan, 2012).

\subsection{Problem Statement}

The purpose of this study is to find out whether new entrants of an organization have positive effects on their reputation while forming groups and socializing with colleagues since orientation. (Beugré \& Psychology, 2010).

The term "Socialization" refers to a process through which individuals gain the information, language, knowledge, values, and social skills to conform to the roles and norms set and required for merging into a community. Within an organizational setting, the process of new employees becoming familiar and sensitive to the informal and the formal power structure and rules of behavior is known to be as socialization. This research paper helps in determining the positive or negative effects of socialization on new employees' reputation within organizations and the process of them being influenced and forming groups (Wang, Kammeyer-Mueller, Liu, \& Li, 2015).

Workers inside association frame bunches through conveying formally and casually. The general population who are more social inside an association tends to positively affect their reputation when they know the strategies of conveying peer connections productively. As abnormal state of socialization may paint a picture of being more social and less mindful towards your work (Tyran, Gibson, \& Management, 2008).

\subsection{Research Question}

This research examines the relationship among the three independent variables and one dependent variable. The question in this research is the extent of the impact that employee reputation can have due to more or less socialization of an employee in an organization or forming alliances or positive relationship with existing employees.

\subsection{Purpose of Study}

This study sets to focus on the organizational practices of socialization and communication 


\section{Macrothink}

International Journal of Human Resource Studies

ISSN 2162-3058 2019, Vol. 9, No. 2

levels available and being utilized to new employees. It caters to the extent to which these widespread, or as we know, practices are looked at by newcomers as being helpful in becoming effective organizational members. This study also talks about new employees' perception towards socializing and grouping amongst themselves or with colleagues. It will also cater to the developed thought of socializing within organization affecting employees' reputation in a positive manner.

\subsection{Significance of Study}

This study will help in exploring the newcomers' role of proactive socialization and individual differences strategies in developing an employee's status in the organization. The research will investigate whether being more social in the corporation is highly effective in bringing out positive image of employee. The hoped findings are the direct relationship among the variables.

\subsection{Definitions}

\subsubsection{Deontic Concept}

Relating to or expressing moral duty or obligation.

\subsubsection{Deontic Concept}

Relating to or expressing moral duty or obligation.

\subsubsection{Heterogeneity Characteristics}

The quality or state of being diverse in character or content.

\subsubsection{Esprit De Corps}

An emotion of self-esteem and loyalty in between the fellows of group.

\subsubsection{LMX}

Leader Member Exchange

\subsubsection{OCB}

Organizational Citizen Behavior

\subsubsection{Somatic Complaints}

It means having a great emphasis on symptoms of the body, for example fatigue or aches, that too to a point where it might or does cause anxiety, depression and other distresses and creates problems while functioning.

\section{Literature Review}

\subsection{Empirical Review}

\subsubsection{Social Network}

The research aimed to study the various aspects like influence of employee socialization on 
organization commitment. The researcher discussed about the critical phase of a new employee is when the entrant must manage relationship with employees and the organization itself. The researcher examined the case of the company in Jordan, the hurdles new employees face and how the organization facilitate the hurdles (Judeh, 2011).

Wang et al. (2015) examined the Newcomers' Relationships of how social network helps in forming ties and socializing. Variables used in this research article were the newcomers' strength in relation to role clarity, organizational knowledge and task mastery. It also focused on the newcomers' social network within the organization in relation to their organizational commitment and social integration. It also determined that there will be a positive relationship between commitment and status and range of an individual's friendship network. Commitment towards the organization increased when newcomers' friendship networks had different individuals from different levels and subunits, and when newcomers had larger networks, their social integration was stronger. It was further recommended in the research that such researches will not only enhance understanding of how newcomers grasp the behavior, attitudes, and knowledge that they need to function successfully in their respective organizations but will also make us comprehend the role of social networks within organizations.

The reason that a new representative can confront a problem when join the association, the association focus on the best way to decrease the vulnerability. To achieve fruitful authoritative socialization, passionate connections toward the association is required. Further, social cooperation from different representatives are vital in the procedure of authoritative socialization. The effective association tries to change new workers, through productive socialization program, into set up hierarchical representatives (Saks \& Gruman, 2011).

Dawley, Andrews, Bucklew, and Journal (2008) researched on supervisor support, mentoring, and perceived organizational support. They used the variables mentoring, perceived organizational support, supervisor support, job search behavior, and organizational commitment. The sample size selected was 346 employees as respondents and method for data collection was done through surveys amongst those respondents. Regression model was applied to the data that was collected and it was found out that the strongest factor for high organizational commitment was perceived organizational support. It was greater than mentoring or supervisor's support, which in comparison failed to develop commitment towards the organization. It was not, however, fully negated that supervisor support of mentoring do not contribute towards development of an organization's workforce and leadership, but the fact that perceived organizational support prevails in this matter could not be denied either. The only drawback of this study that was conducted is that the data was taken from a single manufacturing firm in the US and hence cannot be generalized. The results from this research also suggested that leaders in an organization should fully address programs of organizational - support including rewards, job conditions, and fair operating procedures.

\subsubsection{Relationship Between Employees}

Tyran et al. (2008) examined relationship amongst deep and surface level heterogeneity 
characteristics, Team Reputation, and Group Efficacy. They used the variables collectivism cultural values and tenure, gender and ethnicity and their influence on team outcome, team efficacy, and team reputation. The data was collected from a sample size of 57 teams and groups belonging to the banking industry sector. The research results showed the contrary of hypothesis made. The result showed a positive relationship between group efficacy and collectivism heterogeneity, and a negative relationship between team reputation and ethnic heterogeneity. The research also talked about the implications for theories of international management, group development, and social cognition.

Vitell and Singhapakdi (2008) researched on the role of ethics institutionalization in affecting esprit de corps, organizational commitment, and job satisfaction. They used both explicit as well as implicit forms of institutionalization of ethics commitment towards organization, esprit de corps, job satisfaction, organizational socialization, age relative, and ethical relativism. The investigation was done on marketing professionals and data was collected from them respectively. The results of the research indicated that at least ethics' one of the forms of institutionalization is a prevalent factor of all the three organizational climate constructs. Although, where socialization in the organization is a significant factor of all three variables of organizational climate, the only determinant significant in finding and measuring of the commitment in a negative direction towards organization is relativism. In determining job satisfaction, only age is significant.

Kim, O'Neill, and Cho (2010) examined as of when does an employee of an organization not help his/her coworkers? This study helped in determining the effect of leader-member exchange on employee envy and organizational citizenship behavior which basically meant organizational socialization and its impact on employee behavior and reputation. In their research, they used the variables envy, leader-member exchange, and organizational citizen behavior. The sample size was 233 respondents who belonged to the domain of hotels and worked as front line hotel employees. Path analysis was used on the collected data through which the results were complied. The results showed that workers who have a bad working relationship and bad communication with their respective supervisor, which means low leader-member exchange, tend to show greater levels of envy in comparison to the employees who have somewhat closer working relationships with the same respective supervisor, which means high leader-member exchange. Finally, a decrease in voluntary behavior of helping was found towards coworkers because of higher levels of envy.

Venkataramani, Green, and Schleicher (2010) researched upon the effects on member's work attitudes because of leaders' social network ties. The researchers used variables that were social ties, leader-member exchange, turnover intentions, and employees' job satisfaction. The sample size from which data was collected was 184 and they were bank employees that worked within 42 branch managers at the respective banks. It was found that those leaders with greater and stronger quality relationships with their bosses, also those who were more in connection with their peer networks were thought of and looked up as by their subordinates as having a higher status in their respective organization and, ultimately, were able to establish a higher quality connection and relationship with them. Moreover, the impacts of the leaders' perceived status on Leader Manager Exchange were powerful when subordinates 
were not so central in their own peer network. Eventually, Leader Manager Exchange moderated the effect of perceived status of leaders in their organization on job satisfaction of the subordinates and turnover intentions.

Song, Chon, Ding, and Gu (2015) evaluated job satisfaction and work engagement with the variables core self-evaluation and organization socialization tactics. The researcher study about the CSE and how it helped in job satisfaction and work engagement. The study found that core self-evaluation can help new employee to adjust in a new environment. The data was collected from hotels in China.

\subsubsection{Ethical Values and Attitudes}

Beugré and Psychology (2010) researched on resistance to socialization into the organizational corruption, which basically targeted the employee's harmful attitude of corruption and reputation in accordance with socialization. In this research, variables used were deontic justice model and reduction in engagement of corrupt practices. The data was collected and compiled using the deontic conceptual framework. Result showed that deontic model's fundamental premise of corruption within an organization is that the new entrants with powerful deontic values are more likely to control their getting socialized into corruption, also consider taking the actions necessary in reducing the corrupt attitudes lying in organization in comparison to those who have weak deontic principles. The research model also proposed that the newcomers who have powerful and strong deontic values are presumed to resign or quit the corrupt organizations more in comparison to those with weak deontic principles. It was suggested that a deonance scale could be built to measure the effect of deontic values towards resistance to socially corrupt nature and it can be used to train people in future regarding moral rights and fairness.

\subsection{Research Framework}

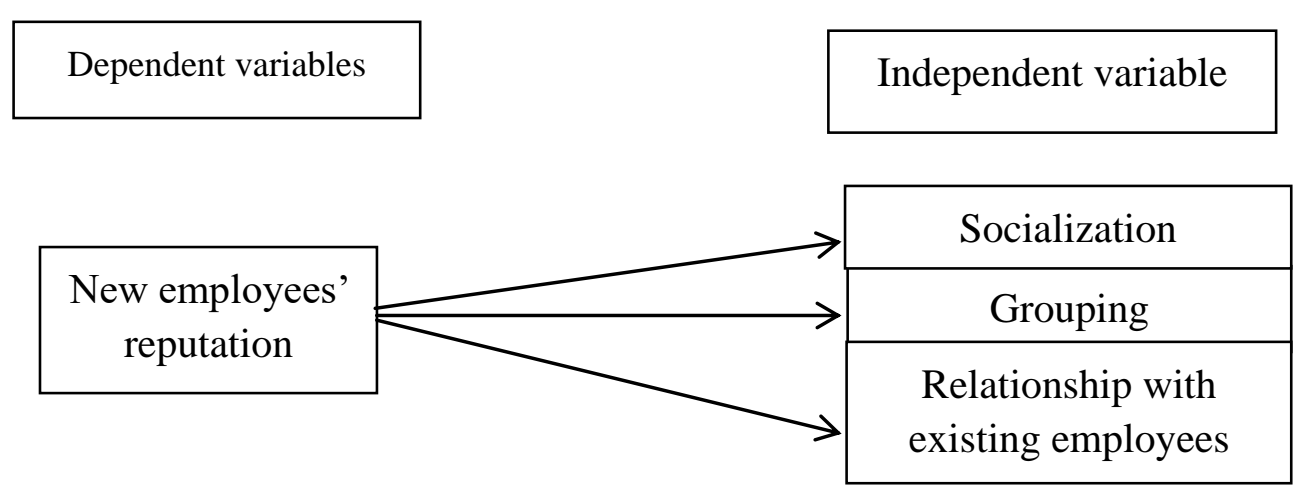

Figure 2.2.1.

The research framework explains the relationship between new employees' reputation with socialization, grouping and relationship with existing employees. In this research the impact of the three-independent variable on dependent variable will be tested. 


\subsection{Hypotheses}

H1: Socialization has a positive impact on new employee's reputation.

H2: Grouping has a positive impact on new employee's reputation.

H3: Relationship with existing employees has a positive impact on employee's reputation.

\section{Research Methodology}

\subsection{Research Approach}

The research is based on getting an idea regarding the relationship between three independent and one dependent variable. The exploratory research helps in finding how and why the independent variable impact dependent variable. To know the impact of socialization, grouping and relation with existing employees on employee's reputation, the exploratory research is being carried out. Socialization, an independent variable and the questions taken for this variable were from a paper that revolves around networking with people. Similarly questions for the independent variable grouping were taken from the same paper that discusses about communication and developing connections at organization (Zinko et al., 2012).

The relationship with existing employees and dealing with people has been explained in the research paper and the questions were taken from the paper (Ferris et al., 2005).

The questions for dependent variable were taken from the research paper regarding employee reputation and how people and the employee think about the certain situations (Cavazza, Guidetti, \& Pagliaro, 2015).

\subsection{Research Design}

The research problem is to find the impact of socialization, grouping and relationship with colleagues on the rapport of employee. Correlational research design is used to discover the relation among all the variables.

\subsection{Sampling Design}

Simple random sampling as the research sampling design was used in this study to obtain a result that is scientific so that it could be used to portray the entire population and it was also chosen for a nonbiased result.

\subsubsection{Target Population}

The sample size in this research was taken from different organizations and institutions. Respondents were mainly the new comers and managers, regardless of age or gender, that were randomly selected.

\subsubsection{Sample Size}

The respondents that were randomly selected, asked for consent, and were given 
questionnaires to fill until the desired number of 250 respondents was reached.

\subsubsection{Sampling Technique}

Probability sampling is used as a technique of sampling for the conducted research. The respondents were selected randomly from different institutions and organizations, as done in simple random sampling.

\subsection{Instrument of Data Collection}

The data for this research was collected through the developed structured questionnaire, depending upon the respondent's availability, time, and resources. The data for this research has been collected from different sources such as research papers, articles, journals, books and internet. For primary data, questionnaires were used mostly with new employees and managers in a reputable organization. As per the secondary data, majority of it was collected from academic sources such as articles, internet, and journals. Articles and research papers were mainly taken from Jstor, Springer, Emerald Insight which were easily available.

\subsubsection{Reliability and/or Validity of Instrument}

Pilot testing was done through giving questionnaires to a sample size of 30 respondents to check the questionnaire's reliability.

\subsection{Procedure of Data Collection}

Questionnaires were given out to the respondents of random organizations and universities to collect data for statistical representation in the study from employees and students who are newly employed.

Quantitative research data collection method was done for this topic to get better insights regarding the phenomena of employees' behavior within organization. The "how" and "why" of dependency of employees' reputation because of grouping and socialization within an organization was found out. Besides the quantitative research data collection method was also used to find out about the phenomenon through numerical representations and statistical representation.

\subsection{Statistical Technique}

It comprised of three independent variables that are socialization, grouping, and relationship with existing employees; and one dependent variable that is new employee's reputation. Reliability in all the variables was found. Furthermore, the questionnaire was then dispersed into larger sample size for gathering of data and for calculating of the results.

Multiple Linear Regression technique has been used for the data analysis and interpretation.

\section{Result}

The research of this study helped in finding the relationship of socialization and other independent variables with new employee reputation. Results suggest that grouping does not impact the new employee's reputation. The employee is free to decide whether he wants to 
form groups in the organization or be a productive team player. The decision will not influence the worker's status in the organization. The worker can stay friendly with or without forming groups to build a positive image. The independent variable grouping is not affecting new employee's reputation as shown in the results.

Bauer, Bodner, Erdogan, Truxillo, and Tucker (2007) discuss the problems and behaviors faced by the new entrant in an organization. This research tells about the problems new employees face while adjusting to the culture and people. The three important variables in this research are role clarity, self-efficacy, and social acceptance. The variable social acceptance is linked with the results of this research finding. The relationship with existing employees and socialization among employees help the new entrant to get adjusted.

Table 4.1.

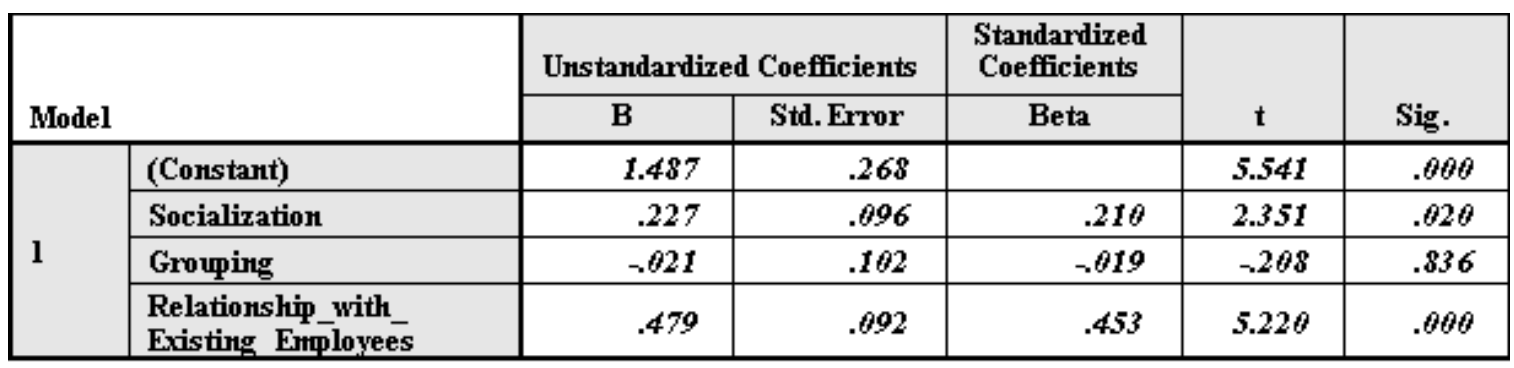

The significance level of grouping is above 5\% which clearly shows that there is no significant impact of the independent variable grouping on the dependent variable employee reputation.

On the contrary other two independent variables socialization and relationship with existing employees; have significant impact on the dependent variable. The new worker must socialize and mingle with people to paint a positive picture of himself. The idea of connecting with colleagues productively can result in a constructive visual of the employee's rapport.

\subsection{Descriptive Profile of the Data}

Table 4.2.

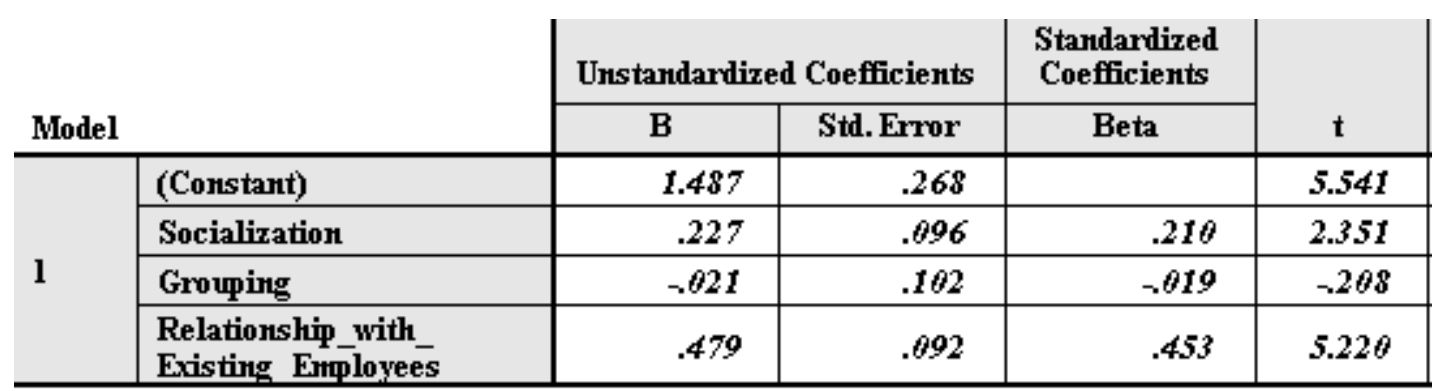

The T-value needs to be greater than 1.96 for the variable to be accepted. Here the T value of socialization and relationship with existing employees is greater than 1.96, indicating the strong relationship with the dependent variable. Grouping has a T-value less than 1.96 indicating that it does not have any significant impact. 


\subsection{Validation of Model}

Table 4.3.

\begin{tabular}{|}
\hline \multicolumn{2}{|c|}{ Reliability Statistics } \\
\begin{tabular}{|c|r|}
\hline $\begin{array}{c}\text { Cronbach's } \\
\text { Alpha }\end{array}$ & N of Items \\
\hline .829 & $2 \theta$ \\
\hline
\end{tabular}
\end{tabular}

The data collected passed the reliability test. The data collected initially by 30 respondents was done pilot testing to check the validity/reliability of the model. The test run was Cronbach's Alpha and the result was $8.2 \%$ that means the data collected was reliable.

\subsection{Hypotheses Testing}

H1: Socialization has a positive impact on new employee's reputation.

H2: Grouping has a positive impact on new employee's reputation.

H3: Relationship with existing employees has a positive impact on employee's reputation.

The hypotheses taken were tested and checked for reliability through reliability analysis initially and then through multiple regression analysis. The results of reliability analysis proved that the hypotheses are valid.

\subsection{Hypotheses Assessment Summary}

Table 4.4.

\begin{tabular}{|c|l|c|c|}
\hline S.No & \multicolumn{1}{|c|}{ Hypothesis } & Sig Value & Conclusion \\
\hline H1 & $\begin{array}{l}\text { Socialization has a positive impact on new } \\
\text { employee's reputation. }\end{array}$ & 0.020 & Accepted \\
\hline H2 & $\begin{array}{l}\text { Grouping has a positive impact on new } \\
\text { employee's reputation. }\end{array}$ & 0.836 & Rejected \\
\hline H3 & $\begin{array}{l}\text { Relationship with existing employees has a } \\
\text { positive impact on employee's reputation. }\end{array}$ & Accepted \\
\hline
\end{tabular}

The $\mathrm{H} 1$ has a sig value of 0.020 i.e $2 \%$ and it is less than $5 \%$ so the $\mathrm{H} 1$ is accepted and the sig value signals that there is impact of level of socialization and employee does in a corporation on the employee's reputation.

The $\mathrm{H} 2$ has sig value higher than $5 \%$, it is $8.3 \%$ so it tells that there is no significant impact of grouping on the status of the worker in the organization.

The $\mathrm{H} 3$ result tells that there is an impact on relationship with existing employees on their 
reputation of the employee because the sig value is lower than $5 \%$.

\section{Conclusion}

Mujtaba, Sims, and Psychology (2006) examined the socializing of retail employees and the effectiveness of formal versus informal methods of socialization. The research related to this article because it showed impact of socialization on employees. They used the variables: informal socialization process, formal socialization process, employee attitude, unethical behavior. The sample size was 203 full time employees using informal process for socialization and 274 managers using formal process for socialization. The results indicated that full time employees who used the process of informal socialization and communication were more towards accepting unethical behavior and were tolerant of such attitude. However, managers who used a formal process of communication and socialization were not readily agreed towards unethical behavior or any of such attitudes. This led us to a conclusion that to implement and to work on eradicating unethical behavior and practices in any given organization, formal socialization is a much better way in comparison to informal socialization process.

The purpose of this research was to find out if the socialization really helps in building a constructive image of a worker. By getting the sig value for socialization less than $5 \%$ tell that it really impacts the image of the employee.

The research tells about how an employee has issues in socialization because of new environment and culture. The researcher van der Werff and Buckley (2017) examined how the new employees react to a certain situation and trust existing employee. To trust a new person is hard and the entrant has no clue whom to trust. Initially the new employee develops positive relationships but by the time pass an employee can find it hard to take the decision of who to trust.

So the findings of this research tells about the balance a new employee can maintain while socializing in a new firm.

\subsection{Discussion}

The sig value for two independent variables is less than 5\% which indicates the importance of variables for the employee to bring out the positive image. The independent variable grouping has shown no relation with the dependent variable that means it does not matter if the employee has grouping as habit to build up his image. In this research, results suggested that being social in the organization can help the employee for his career growth but the

The results demonstrated that social responsibility and reconciliation is adversely identified with the system size of companionship in any case, emphatically identified with the quality of fellowship in the corporation. It likewise verified that there will be a positive connection amongst responsibility and status and possibility of a person's fellowship position (Wang et al., 2015) 


\subsection{Implications}

This research is helpful for the new employees who join the organization but do not know the technique to figure out the key to success and outstanding image in front of colleagues or supervisors. The basic purpose of this research was to know the level of socialization an employee can do for producing effective results. So, this research can help employees to know the point where socialization can start and stop.

\subsection{Limitations}

The limitations in this research are difference in the gender while socialization. In this research findings, males and females have different perceptions in an organization related to socialization in the organization. Males might be considered as friendlier while they are social, but the case is not same with females. People think differently for both the genders as well as both genders think differently too.

\subsection{Recommendations}

To create awareness regarding the topic, it is necessary to research further on the topic so more people can come to know about the importance of being social in an organization. Also, the research findings will help to know the extent of friendliness an employee can pursue to have a good image in office.

As discussed by the researchers Saks and Gruman (2011) the new employee face difficulties in getting to know the organization, culture and people; it would be helpful to motivate employees and new entrants to research regarding the level of socialization, and how to build relationship with existing employees to make sure that people know a new employee has joined the organization.

\section{Acknowledgement}

Above all else thank to Almighty "ALLAH" who is most tolerant and kind to the majority of his manifestations with no segregation and who makes me ready to set up this research report.

I generously appreciative to my research supervisor, Dr. Asim, whose consolation, help and support from the initial step to the last level empowered me to build up an understanding of the methodology of conducting research and empowered me to build up a comprehension of the approach of leading exploration.

My research work has benefited from the insightful direction of numerous colleagues, teachers, employees and more numerous than I can fully acknowledge here. I would like to acknowledge those who participated in the occasions that I conducted interviews to get formal feedback on my research topic that is "Impact of Socialization on Employee's Reputation.”

Finally, I offer my respects and endowments to all those who supported and promoted me in any regard amid the fulfilment of the research. 


\section{References}

Bauer, T. N., Bodner, T., Erdogan, B., Truxillo, D. M., \& Tucker, J. S. J. J. o. a. p. (2007). Newcomer adjustment during organizational socialization: a meta-analytic review of antecedents, outcomes, and methods. 92(3), 707. https://doi.org/10.1037/0021-9010.92.3.707

Beugré, C. D. J. J. o. B., \& Psychology. (2010). Resistance to socialization into organizational corruption: A model of deontic justice, 25(3), 533-541. https://doi.org/10.1007/s10869-010-9176-3

Carpenter, M., Bauer, T., \& Erdogan, B. J. R. J. (2012). Management Principles. V. 1.0. Creative Commons. 20, 2017.

Cavazza, N., Guidetti, M., \& Pagliaro, S. J. C. P. (2015). Who cares for reputation? Individual differences and concern for reputation, 34(1), 164-176. https://doi.org/10.1007/s12144-014-9249-y

Dawley, D. D., Andrews, M. C., Bucklew, N. S. J. L., \& Journal, O. D. (2008). Mentoring, supervisor support, and perceived organizational support: what matters most? , 29(3), 235-247. https://doi.org/10.1108/01437730810861290

Ferris, G. R., Treadway, D. C., Kolodinsky, R. W., Hochwarter, W. A., Kacmar, C. J., Douglas, C., \& Frink, D. D. J. J. o. m. (2005). Development and validation of the political skill inventory, 31(1), 126-152. https://doi.org/10.1177/0149206304271386

Judeh, M. J. I. B. R. (2011). Role ambiguity and role conflict as mediators of the relationship between orientation and organizational commitment, 4(3), 171. https://doi.org/10.5539/ibr.v4n3p171

Kim, S., O’Neill, J. W., \& Cho, H.-M. J. I. J. o. H. M. (2010). When does an employee not help coworkers? The effect of leader-member exchange on employee envy and $\begin{array}{llll}\text { organizational citizenship 530-537. } & \text { behavior. }\end{array}$ https://doi.org/10.1016/j.ijhm.2009.08.003

Mujtaba, B. G., Sims, R. L. J. J. o. B., \& Psychology. (2006). Socializing retail employees in ethical values: The effectiveness of the formal versus informal methods. 21(2), 261-272. https://doi.org/10.1007/s10869-006-9028-3

Saks, A. M., \& Gruman, J. A. J. J. o. M. P. (2011). Getting newcomers engaged: The role of socialization tactics. 26(5), 383-402. https://doi.org/10.1108/02683941111139001

Song, Z., Chon, K., Ding, G., \& Gu, C. J. I. J. o. H. M. (2015). Impact of organizational socialization tactics on newcomer job satisfaction and engagement: Core self-evaluations as moderators. 46, 180-189. https://doi.org/10.1016/j.ijhm.2015.02.006

Tyran, K. L., Gibson, C. B. J. G., \& Management, O. (2008). Is what you see, what you get? The relationship among surface-and deep-level heterogeneity characteristics, group efficacy, and team reputation. 33(1), 46-76. https://doi.org/10.1177/1059601106287111

van der Werff, L., \& Buckley, F. J. J. o. M. (2017). Getting to know you: A longitudinal examination of trust cues and trust development during socialization. 43(3), 742-770. https://doi.org/10.1177/0149206314543475

Venkataramani, V., Green, S. G., \& Schleicher, D. J. J. J. o. A. P. (2010). Well-connected leaders: The impact of leaders' social network ties on LMX and members' work attitudes. 95(6), 1071. https://doi.org/10.1037/a0020214

Vitell, S. J., \& Singhapakdi, A. J. J. o. B. E. (2008). The role of ethics institutionalization in 


\section{Macrothink}

International Journal of Human Resource Studies

ISSN 2162-3058 2019, Vol. 9, No. 2

influencing organizational commitment, job satisfaction, and esprit de corps. 81(2), 343-353. https://doi.org/10.1007/s10551-007-9498-X

Wang, M., Kammeyer-Mueller, J., Liu, Y., \& Li, Y. J. O. P. R. (2015). Context, socialization, and newcomer learning. 5(1), 3-25. https://doi.org/10.1177/2041386614528832

Zinko, R., Ferris, G. R., Humphrey, S. E., Meyer, C. J., Aime, F. J. J. o. O., \& Psychology, O. (2012). Personal reputation in organizations: Two-study constructive replication and extension of antecedents and consequences. 85(1), 156-180. https://doi.org/10.1111/j.2044-8325.2010.02017.x

\section{Copyright Disclaimer}

Copyright for this article is retained by the author(s), with first publication rights granted to the journal.

This is an open-access article distributed under the terms and conditions of the Creative Commons Attribution license (http://creativecommons.org/licenses/by/4.0/). 